\title{
Transcatheter bilateral superselective arterial embolization, a minimally invasive method for persistent hematuria in elderly and comorbid patients with bladder and prostate cancer
}

\author{
Mesane ve prostat kanseri olan yașlı ve komorbid hastalarda dirençli hematüride minimal \\ invaziv bir yöntem, transkateter bilateral süperselektif arter embolizasyonu
}

\author{
Eser Ordek ${ }^{1}$, Mehmet Kolu ${ }^{2}$, Mehmet Demir ${ }^{1}$, Eyyup Sabri Pelit ${ }^{1}$, Halil Ciftci ${ }^{1}$ \\ 1 Harran University, Faculty of Medicine, Department of Urology, Sanlıurfa, Turkey \\ 2 Harran University, Faculty of Medicine, Department of Radiology, Sanlıurfa, Turkey
}

Submitted: 2020-12-23

Accepted: 2021-03-21
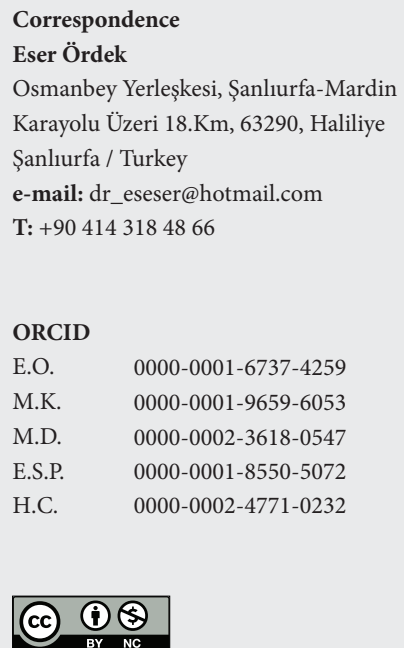

This work is licensed under a Creative Commons Attribution-NonCommercial 4.0 International License.
Özet

Amaç: Bu makalede yaşlı ve komorbid hastalarda mesane ve prostat kanserine bağlı tekrarlayan dirençli hematürilerde bir tedavi seçeneği olarak transarteriyel mikrokateter yöntemi ile uygulanan süperselektif vezikal ve prostatik arter embolizasyonu tecrübemizi paylaşmayı amaçladik.

Gereç ve Yöntemler: Mesane ve prostat kanseri tanılarına bağlı makroskopik hematüri sebebiyle kliniğimizde takip-tedavisi sürdürülen, komorbidite (geçirilmiş serebrovasküler hastalık ve koroner arter hastalığı) ve yüksek cerrahi operatif risk sebebiyle diğer palyatif ve radikal cerrahi yöntemlerle tedavi edilemeyen 10 hastaya transarteriyel mikrokateter yöntemi ile bilateral süperselektif vezikal veya prostatik arter embolizasyonu işlemi uygulandı. Embolizasyon tedavisi öncesi ve sonrasında; hastaların hemoglobin $(\mathrm{Hb})$ ve hematokrit (Hct) değerleri, uygulanan kan-kan ürünleri transfüzyon miktarı, gelişen postoperatif komplikasyonlar, üretral foley kateter çekilme süreleri ile hasta memnuniyet derecesi değerlendirildi. Hastalar ortalama 15 ay süresince aralıklı olarak kontrollerle takip edildi.

Bulgular: Çalışmaya dahil edilen hastaların ortalama yaşı 77,5 (69-86) yıl idi. Embolizasyon işlemi öncesi hastalara ait ortalama $\mathrm{Hb}$ değeri 8,16 $\mathrm{mg} / \mathrm{dl}$ ve işlem sonrası ortalama $\mathrm{Hb}$ değeri 9,48 $\mathrm{mg} / \mathrm{dl}$ olarak hesaplandı. Ortalama Hct değerleri ise işlem öncesi 25,5 ve işlem sonrası 30,4 idi.

\section{Abstract}

Objective: In this article, we aimed to share our experience with superselective vesical and prostatic artery embolization applied by transarterial microcatheter method as a treatment option for recurrent resistant hematuria due to bladder and prostate cancer in elderly and comorbid patients.

Materials and Methods: Bilateral transarterial microcatheter method was used for superselective vesical or prostatic artery embolization in 10 patients whose follow-up treatment was continued in our clinic with macroscopic hematuria due to bladder and prostate cancer diagnoses and could not be treated with other palliative and radical surgical methods due to comorbidity and high surgical operative risk. Before and after embolization treatment; hemoglobin $(\mathrm{Hb})$ and hematocrit $(\mathrm{Hct})$ values of the patients, the amount of transfusion of blood and blood products, postoperative complications, urethral foley catheter removal times and patient satisfaction were evaluated. The patients were followed up with controls intermittently for an average of 15 months.

Results: The mean age of the patients included in the study was 77.5 (69-86) years. The average hemoglobin value before and after the embolization procedure was $8,16 \mathrm{mg} / \mathrm{dL}$ and $9,48 \mathrm{mg} / \mathrm{dL}$, respectively. The average hematocrit value before and after the embolization procedure was 25,5 and 30,4 , respectively. The average amount of

This study was approved by the Harran University Ethics Committee of Clinical Researches (Approval number: HRU/20.22.10, Dec 21, 2020). All research was performed in accordance with relevant guidelines/regulations, and informed consent was obtained from all participants. 
Ortalama kan ürünleri (eritrosit süspansiyonu) transfüzyonu miktarları ise işlem öncesi 2.1 (1-3) ünite olup işlem sonrası takiplerde kan transfüzyonu ihtiyacı olmadı. Hastaların tümünün üretral kateterleri idrar rengi tamamen berrak hale geldikten sonra ortalama 5. günde (3-7 gün) çekildi. Postop hicbir hastada girişime bağlı majör komplikasyon, tekrar üretral kateterizasyon ya da mortalite, morbidite meydana gelmedi.

Sonuç: Yaşlı ve komorbiditesi olan hastalarda mesane veya prostat kanserine bağlı meydana gelen ve yüksek anestezi riski sebebiyle diğer palyatif yöntemlerle kontrol altına alınamayan dirençli hematüri durumunda transarteriyel mikrokateter yöntemi ile uygulanan süperselektif vezikal ve prostatik arter embolizasyonu tedavisi etkin ve güvenilir bir alternatiftir.

Anahtar Kelimeler: dirençli hematüri, mesane kanseri, süperselektif vezikal arter embolizasyonu blood products (erythrocyte suspension) transfusion was 2.1 (1-3) units before the procedure, and there was no need for blood transfusion in the follow-up after the procedure. The urethral catheters of all patients were removed on the 5th day (3-7 days) after the urine color became completely clear. There were no major complications, recurrent urethral catheterization or mortality, morbidity related to the treatment after the embolization procedure.

Conclusion: Superselective vesical and prostatic artery embolization treatment applied by transarterial microcatheter method is an effective and reliable alternative in the case of resistant hematuria due to bladder or prostate cancer that cannot be controlled with other palliative methods due to the high risk of anesthesia in elderly patients with comorbidities.

Keywords: persistent hematuria, bladder cancer, superselective vesical artery embolization

\section{Giriş}

Mesane veya prostat kaynaklı inatçı hematüri büyük terapötik zorluklar içerir ve bazı durumlarda hayatı tehdit edebilir. Şiddetli hematüri nedenleri çoğunlukla komplet rezeke edilemeyen mesane tümörleri, radyasyon sistiti, siklofosfamid kaynaklı sistit, prostat veya prostat kanserinin transüretral rezeksiyonudur (Resim-1). Bunlar arasında özellikle mesane ve prostat kanseri sık tekrarlayan dirençli hematürilere neden olabilmekte ve bu hastaların önemli bir kısmında hemodinamik bozukluklara yol açarak mortal bir hal alabilmektedir. İşte bu grup hastalarda kanama, irrigasyon ya da endoskopik tedavi yöntemleriyle yeterince kontrol altına alınamayabilir $(1,2)$. Bu hasta popülasyonunda operatif risk yüksek olduğundan radikal cerrahiler ya da genel anestezi gerektiren tekrarlayan endoskopik müdahaleler de her zaman mümkün olmayabilir.

Son yıllarda mesane ve prostat kaynaklı kanamaları kontrol etmede güvenli, etkili bir şekilde kullanılan anjiografi ve embolizasyon minimal invaziv bir yöntemdir. Bu hastalarda diğer tüm tedaviler başarısız olduğunda ya da yüksek operatif riskten dolayı uygulanamadığında, süperselektif vezikal veya prostatik arter embolizasyonu tedavi seçeneği olarak akılda bulundurulmalıdır. Bu prosedürle ilgili sınırlı sayıda yayınlanmış deneyim olmasına rağmen, vezikal veya prostatik arterler doğru şekilde tanımlanıp embolizasyon sağlandığında hastaların \%90'ında başarı oranı bildirilmektedir $(3,4,5)$.

Mesanenin arteriyel beslenmesini sağlayan inferior vezikal arter internal iliak arterin bir dalıdır (6). Pros- tatın arterleri ise sağ ve sol taraflar arasında ve hastalar arasında oldukça değişken kökenlere sahiptir ve çoğu zaman internal iliak arterin dalı olan internal pudendal arterden çıkar. Antero-lateral prostatik pedikül, merkezi bezin çoğunu ve iyi huylu prostat hiperplazisi nodüllerini vaskülarize eder, iki bağımsız prostatik arterli hastalarda sıklıkla superior vezikal arterden kaynaklanır (7). Vakaların yaklaşık \% 60'ında prostat dalları ve onları çevreleyen arterler arasında embolizasyon planlanırken dikkate alınması gereken önemli anastomozlar görülebilir $(6,7)$.

$\mathrm{Bu}$ makalede mesane ve prostat kanseri tanısı ile takipli, operatif riski yüksek olan hastalarda, tekrarlayan dirençli hematürilerin kontrol altına alınması için transarteriyel mikrokateter yöntemiyle süperselektif vezikal arter veya prostatik arter embolizasyonu işlemine ait ilk tecrübelerimizi paylaşmayı amaçladık.

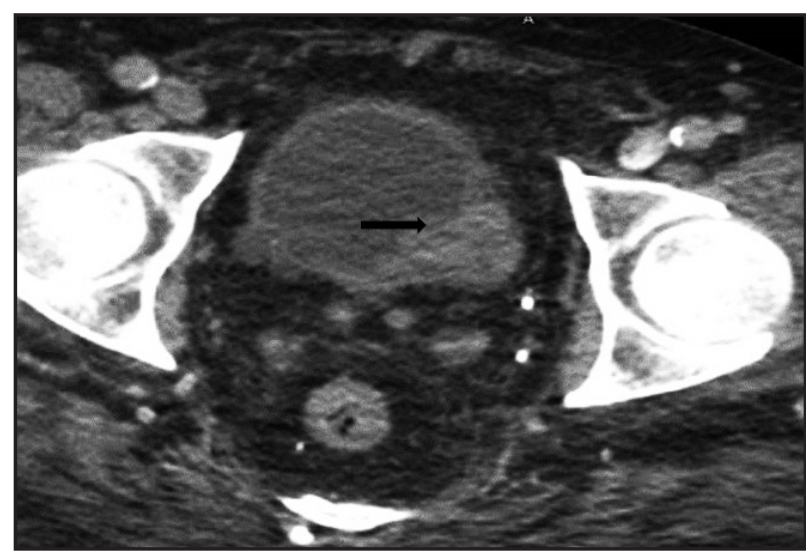

Resim 1. Mesane sol inferolateral duvarda solid yer kaplayıcı kitle lezyonu, ok işareti ile gösterilen (Harran Üniversitesi Üroloji AD). 


\section{GEREÇ VE YÖNTEMLER}

\section{Verilerin Toplanması}

Çalışmaya 2018-2020 tarihleri arasında kliniğimizde mesane ve prostat kanseri tanısı ile takip edilen ve tekrarlayan inatçı hematürinin diğer palyatif yöntemlerle kontrol altına alınamadığı, yüksek operatif risk nedeniyle radikal cerrahi yapilamayan transarteriyel mikrokateter yöntem ile süperselektif vezikal ve prostatik arter embolizasyonu uygulanan hastalar dahil edildi. Çalışma için fakültemiz etik kurulundan onay alındı (HRU/20.22.10). Hasta verileri hastane kayıtlarından retrospektif olarak incelendi. Hastaların yaş, cinsiyet, tanı, embolizasyon işlemi öncesi ve sonrası ortalama hemoglobin ve hematokrit değerleri, kan ve kan ürünleri transfüzyon miktarı, hematürinin işlem öncesi ve sonrasındaki şiddeti, hematürinin sonlanması sonrası transüretral foley kateterin çekilme süreleri kayit edildi.

\section{Hasta Seçimi}

Masif hematüri şikayetiyle kliniğimize başvuran hastalarda ilk planda transüretral kateterizasyon ve devamlı mesane irrigasyonu ile hematüri kontrol altına alınmaya çalışıldı. Endoskopik cerrahi girişim için uygun olan hastalarda kanama TUR (transuretral rezeksiyon,mesane-prostat) ve/veya monopolar enerji kaynağ ile koterize edilerek kontrol altına alınmaya çalışıldı. Endoskopik girişim için genel durumu uygun olmayan ya da endoskopik girişimlere rağmen kanamaları devam eden hastalarda tercih edilebilecek palyatif yöntemler arasında lokal ya da kısa süreli anestezi altında uygulanabilen intravezikal formalin instilasyonu veya bazı pıhtılaşmayı sağlayan ajanların intravezikal instilasyonu sayılabilir. Ancak tüm girişimlere rağmen kontrol altına alınamayan inatçı hematüri varlığında endovasküler embolizasyon fayda sağlayabilecek minimal invaziv bir yöntemdir. Biz de kliniğimizde tekrarlayan endoskopik cerrahi girişimlere ya da transüretral kateter yolu ile uygulanan mesane irrigasyonu gibi palyatif tedavi yaklaşımlarına rağmen kanaması kontrol altına alınamayan ve cerrahi risk nedeniyle radikal cerrahi girişim yapılamayan hastalara alanında tecrübeli girişimsel radyolog ve üroloji asistanı desteğiyle transarteriyel mikrokateter yöntemi ile bilateral süperselektif vezikal arter ve prostatik arter embolizasyonu uyguladık.

\section{Transkateter Süperselektif Arter Embolizasyonu}

Tüm hastalara işlemin potansiyel riskleri hakkında bilgi verildi ve yazılı bilgilendirilmiş onam alındı. Embolizasyon işlemi öncesinde hastaların kullandığı antiagregan, antikoagülan ajanlar kardiyoloji ve nöroloji uzmanlarının önerileri doğrultusunda işlemden on iki saat önce kesildi ve köprüleme tedavisi olarak DMAH (düşük molekül ağırlıklı heparin) tedavisi başlandı. Hastaların tamamına işlem öncesi tek doz iv (intravenöz) antibiyotik verildi. Sterilizasyon sağlandıktan sonra supin pozisyonda, lokal anestezi altında dijital çıkarımlı anjiyografi ünitesinde tüm hastalara sağ femoral arteryal retrograd yaklaşım alınarak $6 \mathrm{~F}$ arteryel akses kılıfı yerleştirildi. Ardından, internal iliak arterlerin selektif anjiyografisi, rutin olarak 5Fr Cobra veya Simmons-tip 2 kateter kullanılarak yapıldı. Kateter ucu daha sonra dallarını opaklaştırmak için internal iliyak arterin ön bölümüne mümkün olduğunca selektif olarak yerleștirildi. Vezikal ve prostatik arterler, hipogastrik arterin ön bölümünün ayrı dalları olarak ortaya çıkabilir (Resim-2). Anjiyografide anormal hipervaskülarite ve hatta kitle görülebilir, ancak ekstravazasyonun görülmesi alışılmadık bir durumdur. Anjiyografik bulgulara dayanılarak vezikal veya prostatik dalların süperselektif kateterizasyonu rutin olarak $3 \mathrm{Fr}$ koaksiyel mikro kateter kullanılarak yapıldı. Akışa yönelik embolizasyon genellikle kontrast madde ile karıştırılmış polivinil alkol (PVA) partikülleri kullanılarak elde edildi (Resim-3). Tipik olarak 300 ila $500 \mu \mathrm{m}$ partiküller kullanıldı. PVA, damarda mekanik blokaj yapan bir ajan olup en çok kullanılan partikül embolizan maddedir. Çapları 150-1180 mikron arasında değișen partiküller halinde hazırlanır. Genellikle oval, düzensiz ve keskin sınırlı olup kümeleşme eğilimindedir.

\section{BULGULAR}

Çalışmaya dahil edilen 10 (9 erkek, 1 kadın) hastanın sekizi mesane ikisi prostat kanseri, hastaların ortalama yaşı 77,5 (69-86) yıl idi. Hastalardan dördü koroner arter hastalığına bağlı antiagregan kullanırken biri de geçirilmiş SVO'ya (serebrovasküler olay) bağlı antikoagülan ve antiagregan kullanmakta idi. Mesane tümörlü hastaların görüntüleme yöntemleri ile saptanan ortalama tümör çapları $42 \mathrm{~mm}$ (25-65 mm) olarak 


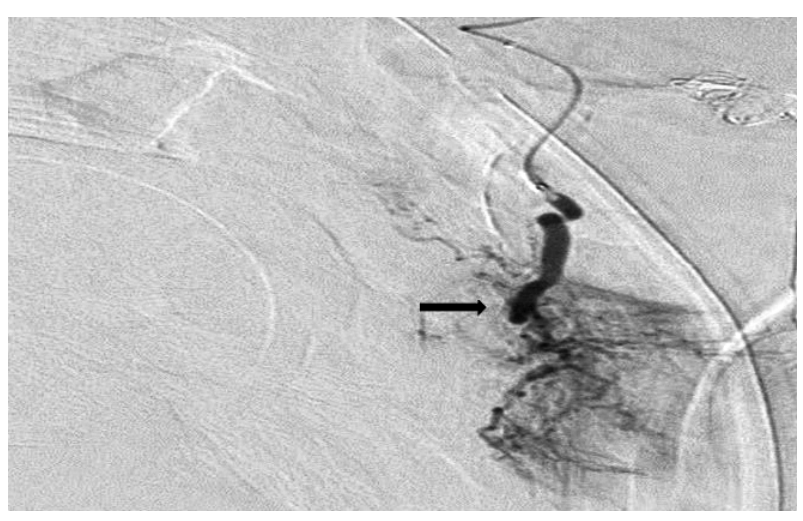

Resim 2. Sol inferior vezikal arterden yapılan selektif anjiogramda blushing tarzda tümör boyanması izlenmektedir, ok ișareti ile gösterilen (Harran Üniversitesi Girişimsel Radyoloji AD).

ölçüldü (Tablo 1). Hastaların en son yapılan TUR-M (transüretral rezeksiyon-mesane) materyallerine ait patolojik incelemede üç hastada pT1 yaygın high grade, beş hastada ise pT2 yaygın high grade ürotelyal karsinom olarak rapor edildi. Prostat kanseri hastaları ise ileri evre metastatik olup patolojileri prostat adenokarsinom, Gleason $4+5$ ve $5+5$ idi.

İşlem öncesi ortalama $\mathrm{Hb}: 8.16 \mathrm{mg} / \mathrm{dl}$, Hct:25.5, işlem sonrasi ortalama Hb:9,48 mg/dl, Hct:30,4 bulundu. Ortalama kan ürünleri (eritrosit süspansiyonu) transfüzyonu miktarı ise işlem öncesi 2.1 (1-3) ünite olarak hesaplandı (Tablo 1). İşlem sonrası kontrollerde anlamlı hemoglobin düşüşü olmayan hastalara kan transfüzyonu yapılmadi.

Embolizasyon sonrasında ek müdahale yapılmadan dokuz hastada idrar renginin postop 6-12. saatte tamamen berrak hale geldiği, sadece bir hastada makroskopik hematüri gelişmesi sebebiyle tekrar işleme alındığ

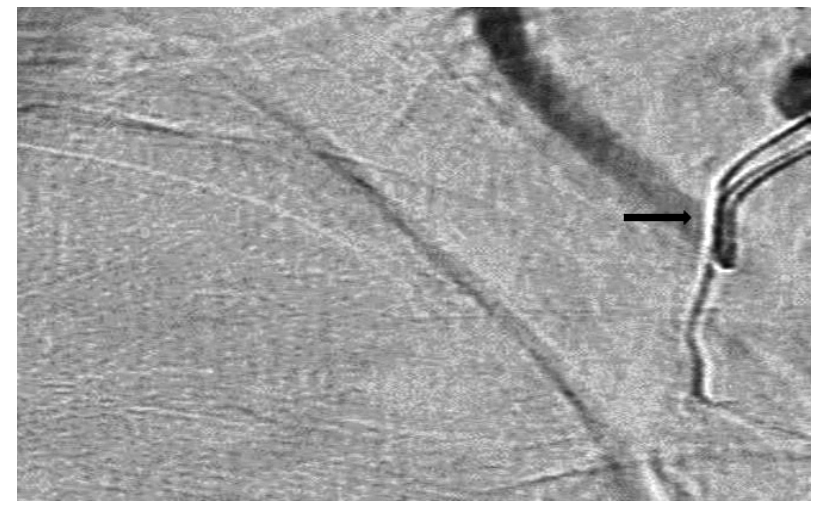

Resim 3. Embolizasyon sonrası tümör boyanması ortadan kalkmış olup besleyici arter tamamen kapatılmış izlenmektedir, ok işareti ile gösterilen (Harran Üniversitesi Girişimsel Radyoloji AD).

gözlendi. Hastaların hastanede yatış süresi ortalama 2 gün (1-3), üretral katater çıkarma ortalama 5 (3-7) günde idi. Embolizasyon işlemi sırasında ya da sonrasındaki ortalama 15 aylık takiplerde hiçbir hastada girişime bağlı majör komplikasyon ya da mortalite görülmedi. İki hastada kateter giriş yerinde hafif derecede ağrı gözlendi ve analjezik tedavisi verildi. Foley kateter çekilmesi sonrasında hastalar miksiyon ihtiyaçlarını normal şekilde giderebildi.

\section{TARTIŞMA}

Dirençli hematüriler, mesane veya prostat kanseri olan hastalarda bazen yüksek morbidite ve mortaliteye sebep olabilmektedir $(8,9,10,11)$. Direçli hematüri varlığında hastanın genel durumu ve eşlik eden hastalıklarına göre farklı tedavi yaklaşımları bulunmaktadır (1). Devamlı mesane irrigasyonu, Helmstein balon kompresyonu ve endoskopik hematom boşaltılması en sık

Tablo 1. Hastalara ait parametreler

\begin{tabular}{ll}
\hline Parametreler & Median değerler (min-max) \\
\hline Ortalama yaş (yıl) & $77,5(69-86)$ \\
İşlem öncesi ortalama Hgb $(\mathrm{mg} / \mathrm{dl})$ & $8,16(6,9-8,9)$ \\
İşlem sonrası ortalama Hgb $(\mathrm{mg} / \mathrm{dl})$ & $9,48(8,7-9,8)$ \\
İşlem öncesi ortalama Hct & $25,5(22-27)$ \\
İşlem sonrası ortalama Hct & $30,4(28-32,2)$ \\
Kan transfüzyon miktarı (ünite) & $2,1(1-3)$ \\
Ortalama tümör çapı (mm) & $42(25-65)$ \\
Ortalama işlem süresi (dk) & $30(25-35)$ \\
\hline Ortalama foley kateter çekilme süresi (gün) & $5(3-7)$ \\
\hline Ortalama hastanede yatış süresi (gün) & $2(1-3)$ \\
\hline
\end{tabular}


kullanılan konservatif yöntemler arasındadır (12). Bu yöntemlerle tedavi edilemeyen hastalarda ise internal iliak arter ligasyonu, sistektomi, prostatektomi gibi radikal cerrahiler son seçenek olarak kullanılmaktadır. Ancak bu tedavi yöntemleri yüksek mortalite ve morbidite ile ilişkilidir. Çünkü dirençli hematürisi olan hastaların çoğu ileri yaşta, koroner arter hastalığı, hipertansiyon gibi komorbiditeleri olan ve antikoagülan ya da antiagregan kulanan hastalardır $(5,13)$. Bu hasta grubunda uzun sureli hospitalizasyon, tekrarlanan endoskopik tedaviler ve sık kan transfüzyonları, bu süreçte meydana gelebilecek ek komplikasyonlar nedeniyle pratik bir tedavi yöntemi değildir. Bu durumda bu grup hastaların takip ve tedavilerinin planlanmasinda minimal invaziv yöntemlerin tercih edilmesinin gerekliliği ön plana çıkmaktadır. Son yıllarda yüksek operatif risk nedeniyle tekrarlayan endoskopik tedavi ya da radikal cerrahi tedavi yapılamayan hastalarda transarteriyel mikrokateter embolizasyon yöntemi yarar sağlayabilecek minimal invaziv bir yöntem haline gelmiştir.

Mesane kanserine bağl1 dirençli hematürisi olan bir hastada tek taraflı internal iliak arter embolizasyonu ilk kez 1974 yılında Hald ve Mygind (14) tarafından, mikrokateter yöntemiyle süperselektif vezikal arter embolizasyonu ise ilk olarak 1980 yılında Kobayashi ve ark. (15) tarafından tanımlanmıştır. İşlemin bu şekilde süperselektif şekilde vezikal arter ya da prostatik artere yapılması ile fazladan arteriyel dalların obstrüksiyonu önlenebileceği, böylece çevre dokuların iskemisi, pelvik ağrı, ürogenital yaralanma ve cilt-doku nekrozu gibi ortaya çıkabilecek potansiyel komplikasyonların azaltılacağı savunulmuştur $(16,17)$. Cho ve arkadaşlarının bildirdiği 2 vaka da komplikasyon olmaksızın başarı ile uygulanmıştır (17). Delgal ve arkadaşlarının mesane ve prostat kanserinden oluşan 20 hastalık serisinde başarı oranı \% 90 olarak bildirilmiş, 15 hasta tek seansta tedavi edilirken 3 hastada ise tekrarlayan girişim gerekmiş. Hastaların 4'ünde komorbitelere bağlı mortalite görülmüş (5). Başka bir vaka serisinde ise erken dönem başarı oranı \%100 olarak bildirilmiştir (13). Bizim serimizde embolizasyon uygulanan 10 hastanın 9'unda tek seansta, 1 hastada ise 2 seansta hematüri kontrolü sağlanmıştır. İkinci seans uygulanan hastada aynı embolizan madde ve aynı teknik uygulanmıştır. Ortalama takip süresi 15 ay olan çalışmamızda hastaların hematüri nedeniyle hastaneye başvurusu olmamıştır. Çalışmamızda ilk seansta başarı oranı \%90, tekrarlayan seans ile birlikte başarı oranı \%100 olarak bulunmuştur.

2016'da Şahin, B. ve arkadaşlarının yaptığı çalışmada mesane kanserine bağlı dirençli hematürili hastalarda süperselektif vezikal arter embolizasyonu uygulanmış olup Girişimsel Radyoloji tarafından uygulanan embolizasyon sırasında n-butil-2-siyanoakrilat (glue) ya da PVA partikülü içeren materyaller kullanılmış (18). Bizim çalışmamızda ise hem mesane hem de prostat kanserine bağlı dirençli hematüri hastaları dahil edildi ve embolizan ajan olarak sadece PVA partikilü kullanıldı.

Emboloterapi, radikal ve tekrarlayan endoskopik cerrahi tedavilere kıyasla düşük komplikasyon oranı ile palyatif amaçlı hastaların yaşam kalitesini iyileştirmede hızlı ve kısa sürede başarı sağlayabilse de mesane ve prostatın zengin arteriyel beslemesi nedeniyle az da olsa organ enfarktüsü riskine sahiptir $(16,17)$. Bildirilen komplikasyonlar genellikle semptomatik ilaçlarla tedavi edilebilen embolizasyon sonrası sendrom vakalarıdır. Ayrıca kalça veya perineal ağrı, Brown-Sequard sendromu, mesane nekrozu, gluteal paralizi veya deri nekrozu şeklinde bildirilen ciddi komplikasyonlar da görülebilmektedir (19). Bu nedenle iskemik komplikasyon riskini minimalize edebilmek için mesanenin veya prostat arterlerinin embolizasyonu mümkün olduğunca süperselektif șekilde yapılmalıdır. Rastinehad ve arkadaşları tarafından süperselektif arter embolizasyonu yapilan hasta serisinde ciddi bir komplikasyon bldirilmemiştir (4). Delgal ve arkadaşlarının bildirdiği hasta serisinde ise komplikasyon oranı $\% 10$ bildirilmiş (5). Bizim çalışmamızda iki hastada katater yerinde ağrı görülürken majör komplikasyon görülmedi. Önceki çalışmalarda da bizim çalışmamızda da embolizasyon sonrası takip süresi kısadır. Bunun sebebinin hasta popülasyonunun ileri evre ve komorbitesi olan hastalardan oluşması nedeniyle hastaların hayatını kaybetmiş olabileceğini düşünüyoruz.

Çalışmamızda bazı kısıtlamalar bulunmaktadır. Bunlardan ilki hasta sayısının az olması ve çalışmanın 
retrospektif olmasıdır. Bunun sebebi ise mesane ve prostat maliğnitelerinden kaynaklı dirençli hematürileri olan ileri yaş hastalarda konvansiyonel ürolojik yöntemlerin ilk seçenek olarak kullanılmasıdır. Diğer bir kısıtllk ise uzun dönem takiplerinin bilinmemesidir.

\section{SONUÇ}

Özetle, transkateter süperselektif arteriyel embolizasyon, etiyolojisi her ne olursa olsun konservatif tedavi başarısız olduğunda ya da yüksek operatif risk sebebiyle cerrahi tedavi yapılamadığında mesane veya prostattan kaynaklı hematürileri kontrol etmede uygulanabilir ve güvenli bir yöntemdir. Özellikle bilateral uygulanan embolizasyon, yaşamı tehdit eden hematürilerin aciliyetini ortadan kaldırır ve kanama kontrolü sağlar, kan transfüzyonu, mesane irrigasyonu ve tekrarlayan sistoskopik müdahaleleri azaltarak palyatif bakım ve yaşam kalitesini iyileștirmeye katkıda bulunur.

\section{Finansal Destek}

Yazarlar bu çalışma için mali destek almadıklarını beyan etmişlerdir.

\section{Çıkar Çatışması}

Yazarlar çıkar çatışması olmadığını beyan ederler.

\section{Etik Kurul}

Bu çalışma Harran Üniversitesi Klinik Araştırmalar Etik Kurulu tarafından 21 Aralık 2020 tarihinde HRU/20.22.10 karar numarası ile etik açıdan uygun bulunmuştur.

\section{KAYNAKLAR}

1. Choong S, Walkden M, Kirby R. The management of intractable haematuria. BJU Int. 2000; 86:951-959.

2. Capelli Schellpfeffer M, Gerber GS. The use of hyperbaric oxygen in urology. J Urol. 1999; 162:647-654.

3. Nabi G, Sheikh N, Greene D, Marsh R. Therapeutic transcatheter arterial embolization in the management of intractable haemorrhage from pelvic urological malignancies: preliminary experience and long-term follow-up. BJU Int. 2003; 92(3):245-247.

4. Rastinehad AR, Caplin DM, Ost MC, et al. Selective arterial prostatic embolization (SAPE) for refractory hematuria of prostatic origin. Urology. 2008; 71(2):181-184.

5. Delgal A, Cercueil JP, Koutlidis N, et al. Outcome of transcatheter arterial embolization for bladder and prostate hemorrhage. J Urol. 2010; 183(5):1947-1953.

6. Bilhim T, Pisco JM, Rio Tinto H, et al. Prostatic arterial supply: anatomic and imaging findings relevant for selective arterial embolization. J Vasc Interv Radiol. 2012 ;23(11):1403-1415.

7. Bilhim T, Tinto HR, Fernandes L, Martins Pisco J. Radiological anatomy of prostatic arteries. Tech Vasc Interv Radiol. 2012; 15(4):276-285.

8. Loffroy R, Pottecher P, Cherblanc V, et al. Current role of transcatheter arterial embolization for bladder and prostate hemorrhage. Diagn IntervImaging. 2014;95(11):1027-1034.

9. El-Zimaity M, Saliba R, Chan K, et al. Hemorrhagic cystitis after allogeneic stem cell transplantation: donor type matters. Blood. 2004; 103:4674-4680.

10. Giné E, Rovira, M Real I, et al. Successful treatment of severe hemorrhagic cystitis after hemopoietic cell transplantation by selective embolization of the vesical arteries. Bone Marrow Transplant. 2003: 31:923-925.

11. Pereira J, Phan T. Management of bleeding in patients with advanced cancer. Oncologist. 2004; 9(5):561-570.

12. deVries CR, Freiha FS. Hemorrhagic cystitis: a review. J Urol. 1990; 143(1):1-9.

13. Prasad V, Sacks BA, Kraus S, Clouse ME. Embolotherapy for lower urinary tract hemorrhage. J Vasc Interv Radiol. 2009; 20(7):965-970.

14. Hald T, Mygind T. Control of life-threatening vesical hemorrhage by unilateral hypogastric artery muscle embolization. J Urol. 1974; 112(1):60-63.

15. Kobayashi T, Kusano S, Matsubayashi T, Uchida T. Selective embolization of the vesical artery in the management of massive bladder hemorrhage. Radiology. 1980; 136(2):345348.

16. Abt D, Bywater M, Engeler DS, Schmid HP. Therapeutic options for intractable hematuria in advanced bladder cancer. Int J Urol. 2013; 20(7):651-660.

17. Cho CL, Lai MH, So HS, Kwok KK, Chan JC, Velayudhan V. Superselective embolisation of bilateral superior vesical arteries for management of haemorrhagic cystitis. Hong Kong Med J. 2008; 14(6):485-488. 
18. Bahadir S, Muhammed S, Ilker T, et al. Super-Selective Embolization of Vesical Arteries with Micro-Catheter Technique in the Treatment of Intractable Hemorrhage due to Bladder Cancer. Bulletin of Urooncology 2016; 15:1-3.
19. Liguori G, Amodeo A, Mucelli FP, et al. Intractable haematuria: long-term results after selective embolization of the internal iliac arteries. BJU Int. 2010; 106(4):500-503. 